\title{
ECONOMIC MODELING OF INTERNATIONAL WATER USE \\ (The Case of the Aral Sea Basin)
}

Yu. M. Ermol'ev

International Institute for Applied Systems Analysis

Laxenburg, Austria

M.V. Mikhalevich

Cybernetics Department, Kiev State University

Ukraine

N.U. Uteuliev

Department of Applied Mathematics, National University

of Karakalpakstan, Usbekistan

RR-95-5

October 1995

Reprinted from Cybernetics and Systems Analysis, Vol. 30, No. 4, 1994.

INTERNATIONAL INSTITUTE FOR APPLIED SYSTEMS ANALYSIS Laxenburg, Austria 
Research Reports, which record research conducted at IIASA, are independently reviewed before publication. Views or opinions expressed herein do not necessarily represent those of the Institute, its National Member Organizations, or other organizations supporting the work.

Reprinted with permission from Cybernetics and Systems Analysis, Vol. 30, No. 4, 1994. Copyright (c)1995 Plenum Publishing Corporation

All rights reserved. No part of this publication may be reproduced or transmitted in any form or by any means, electronic or mechanical, including photocopy, recording, or any information storage or retrieval system, without permission in writing from the copyright holder.

Printed by Novographic, Vienna, Austria. 


\section{Foreword}

This paper presents a procedure for determining an efficient price for water use in areas where there has been no market for pricing. It is based on a novel mathematical innovation developed by the authors. The paper is applied to the Aral Sea region, and it has since been used for the pricing of water in the Chimby Region of Karakalpakstan with interesting results. Without water pricing in this region, which is the situation at present, the most profitable crops are rice and corn. A price on water shifts the production of these crops toward an increase in livestock production. The estimated equilibrium price suggests that water use will decrease by as much as fifteen percent without, however, significant economic losses to the region. The authors suggest that water pricing is a better alternative to a water-use permits market.

Joanne Linnerooth-Bayer

Leader

Risk, Policy, and Complexity 


\section{SYSTEM ANALYSIS}

\section{ECONOMIC MODELING OF INTERNATIONAL WATER USE (THE CASE OF THE ARAL SEA BASIN)} and N. U. Uteuliev

The ecological situation in the Aral region has become particularly acute during the last decade due to rapid drying of the sea and deterioration of water quality in the lower reaches of Amu Darya and Syr Darya. These problems are attracting with increasing frequency the attention of the international community, including environmental scientists, economists, and mathematicians far outside the limits of Central Asia and Kazakhstan.

One of the obvious reasons for the present catastrophe is the uncontrolled use of water resources of the two great rivers, Amu Darya and Syr Darya, which has reduced to unacceptably low levels the inflow to the Aral Sea. This, in turn, has led to a marked increase in the salinity of sea water and to irreversible changes in the microclimate.

Recovery measures are sought in various directions. The session of the Inter-State Coordination Water Commission of the republics of Kazakhstan, Tajikistan, Uzbekistan, Turkmenistan, and Kyrgyzstan held in Nukus (Karakalpakstan) in October 1993 highlighted various aspects of the ecological status of the region. In particular, the participants noted the extreme ecological and socio-economic problems in the Republic of Karakalpakstan, where the proximity of the exposed sea bottom, constant winds raising clouds of salt dust, and poisoned water had led to a significant reduction of life expectancy. The governments of Uzbekistan and Karakaipakstan are naturally undertaking all possible measures to localize the disaster. However, the internal economic resources of Karakalpakstan are clearly insufficient to resolve the problems.

Since the water of Amu Darya and Syr Darya is a common resource of the countries of Central Asia and Kazakhstan, we believe that the hydroecological problems of the Aral region must be tackled by the common efforts of the countries using the water of these two rivers. In particular, possible measures may include the establishment of a joint fund with the participation of the governments in the region whose objective will be to finance ecological improvement projects and to reduce the damage caused by the action of harmful ecological factors. The sources of funds for this institution will be provided by payments from water users. This naturally raises the question of setting scientifically valid charges for water.

The solution of this problem is complex for several reasons. First, in the absence of property rights in water it is difficult to develop market relations with buying and selling of water resources, and market price formation mechanisms thus cannot be expected to provide the right signals. Second, under the specific conditions of Central Asia with its wide spread of irrigated agriculture and permanent water shortages, the utility of water for the users is much higher than the direct material costs associated with water delivery. The cost approach is therefore also inapplicable for setting water prices. Lack of information about the utility functions of water users combined with inaccurate and incomplete information about water use constitute an additional set of difficulties.

Formally, the price of water may be viewed as the shadow price (the dual value) of the optimal water-use program. The main difficulty is how to find the shadow prices without information about the user utility functions. The methodology developed at the International Institute of Applied System Analysis (IIASA) suggests using indirect indicators of utility, such as aggregate water consumption [1]. The values of these indicators can be determined using an interstate ecological monitoring system.

The proposed approach to determining the price of water can be represented by the following abstract model.

Translated from Kibernetika i Sistemnyi Analiz, No. 4, pp. 61-66, July-August 1994. Original article submitted February 2, 1994. 
Consider $N$ countries using a common water resource. First assume that each country uses part of the water without affecting the quality of the remainder. Let $F$ be the available water resources, $x_{i}$ water use in country $i, v_{i}\left(x_{i}\right)$ the profit derived from water use in quantity $x_{i}$ in country $i, \bar{x}_{i}$ the upper limit on water use in country $i$. Then the profit maximization problem for all user countries is stated in the form

$$
\begin{gathered}
\sum_{i=1}^{N} v_{i}\left(x_{i}\right) \rightarrow \max , \\
\sum_{i=1}^{N} x_{i} \leqslant F, \\
0 \leqslant x_{i} \leqslant \bar{x}_{i}, i=\overline{1, N} .
\end{gathered}
$$

It follows from the results of [2] that the solution of this problem is in the core of non-zero-sum games whose players are the $N$ countries with the payoff functions $v_{i}\left(x_{i}\right)$.

Problem (1)-(3) cannot be solved by a single coordinating center, because the player countries are not interested in revealing their utility functions $v_{i}\left(x_{i}\right)$. The IIASA methodology is therefore based on a decentralized algorithm that does not require exchange of information between players.

The algorithm can be described as follows. The coordinating center establishes a certain price for water. The user countries communicate to the center their demand for water at the given price. Depending on the relationship between the aggregate demand for water and the available resources, the coordinating center adjusts the price and notifies the new value to the users. The entire procedure is then repeated. To formalize the procedure, we write the Lagrange function for problem (1)-(3):

$$
L(x, u)=\sum_{i=1}^{N} v_{i}\left(x_{i}\right)+u\left(F-\sum_{i=1}^{N} x_{i}\right)=\sum_{i=1}^{N} v_{i}\left(x_{i}\right)-u \sum_{i=1}^{N} x_{i}+u F
$$

If the optimal solution $u^{*}$ of the dual of problem (1)-(3) is known, we can consider the equivalent formulation (assuming concave utility functions)

$$
\begin{gathered}
L\left(x, u^{*}\right) \rightarrow \max , \\
0 \leqslant x_{i} \leqslant \bar{x}_{i}, i=\overline{1, N} .
\end{gathered}
$$

Using (4), we obtain from (5)-(6) $N$ independent problems

$$
\begin{aligned}
& v_{i}\left(x_{i}\right)-u^{*} x_{i} \rightarrow \max , \\
& 0 \leqslant x_{i} \leqslant \bar{x}_{i}, i=\overline{1, N} .
\end{aligned}
$$

At a given water price $u^{*}$, the solution of the optimal water use problem (1)-(3) is decentralized. The same also holds for an arbitrary price $u$, but in this case the resulting solution is not an optimal solution of problem (1)-(3).

In reality, the exact optimal solution of the dual problem is unknown. However, we can construct an adaptive procedure to find $u^{*}$ using the current imbalance between the aggregate water use $\sum_{i=1}^{N} x_{i}$ and the available resource $F$, i.e., the difference $\sum_{i=1}^{N} x_{i}-F$. The proposed adaptive procedure has the following form. Take an arbitrary number as the initial approximation $u^{0}$. Suppose that $u^{s}$, the price of water at time $s, s=0,1, \ldots$, has been determined. Given this price, each water user determines the own demand $x_{i}^{s}$ by solving the problem 


$$
\begin{aligned}
& v_{i}\left(x_{i}\right)-u^{s} x_{i} \rightarrow \max , \\
& 0 \leqslant x_{i} \leqslant \bar{x}_{i}, i=\overline{1, N} .
\end{aligned}
$$

The new price $u^{s+1}$ is set by changing $u^{s}$ in proportion to the difference between the aggregate demand $\sum_{i=1}^{N} x_{i}^{s}$ and the available supply $F$ subject to nonnegativity of $u^{s+1}$ :

$$
u^{s+1}=\max \left(0, u^{s}+\rho_{s}\left(\sum_{i=1}^{N} x_{i}^{s}-F\right)\right) .
$$

Note that $\sum_{i=1}^{N} x_{i}^{s}-F$ in (11) is the generalized gradient of the objective function $\varphi(u)=\max _{0 \leq x_{i} \leq \bar{x}_{l}} L(x, u), i=\overline{1, N}$.

(Under our assumptions this function is nondifferentiable for $u=u^{s}$ when at least one of the problems (9)-(10) has a nonunique optimal solution [3].) The procedure (11) itself is a generalized gradient descent method [3] for solving the given problem. The stepping multiplier $\rho_{s}$ therefore can be chosen under the standard conditions of this method:

$$
\rho_{s} \geqslant 0, \rho_{s} \rightarrow 0 \text { when } s \rightarrow \infty, \sum_{s=0}^{\infty} \rho_{s}=\infty, \sum_{s=0}^{\infty} \rho_{s}^{2}<\infty .
$$

Note that the coordinating center cannot compute the value of the function $\varphi(u)$ given the available information. The optimal price $u^{*}$ therefore cannot be determined by numerical methods that use this function value.

The last condition guarantees convergence of sequences to one of the optimal solutions $u^{*}$ of the dual of problem (1)(3). Without this condition we can only assert that any convergent subsequence from $\left\{x^{5}\right\}$ converges to $\left\{u^{*}\right\}$.

As we have noted previously, $u^{*}$ may be interpreted as the optimal price of water and $x_{i}^{s}$ as the demand for water of country $i$ at the price $u^{s}$. Relationship (11) is therefore a difference analog of the Walras equaticn that describes the dynamics of prices under specific market conditions and a procedure for the formation of an optimal (i.e., equilibrium) price.

The proposed algorithm simulates a procedure of market price formation for a "common" resource - water. If $x_{i}$ in model (9)-(10) is an $m$-dimensional nonnegative vector, and not a scalar, then problem (9)-(10) is replaced with the following problem:

$$
\begin{gathered}
v_{i}\left(x_{i}\right)-u^{s} \sum_{j=1}^{m} x_{i j} \rightarrow \max , \\
x_{i} \in X_{i}, i=\overline{1, N},
\end{gathered}
$$

where $x_{i}=\left(x_{i 1}, \ldots, x_{i m}\right), i=\overline{1, \ldots, \mathrm{N}}, X_{i}$ is the feasible region.

Note that in reality water is polluted by the users and its quality deteriorates due to effluents and discharges. We therefore need a model that allows for these factors. In this model, the objective function (1) and the constraints (2), (3) are augmented with the constraints

$$
\sum_{i=1}^{N} q_{i}^{k}\left(x_{i}\right) \leqslant Q_{k}, i=\overline{1, N}, k=\overline{1, K}
$$

where $q_{i}^{k}\left(x_{i}\right)$ is the dependence between the volume of water use and the increase of the concentration of the $k$-th pollutant in water, $Q_{k}$ is the maximum admissible concentration of the $k$-th pollutant in water, $K$ is the number of pollutants introduced in the model. In this case, alongside the price $u$ of water we should also impose a tax $w_{k}$ per unit of pollutant $k$ discharged into the water. The adaptive process forming the water price and the pollution tax takes the following form.

Take arbitrary values for $u^{0}$ and $w_{k}{ }^{0}, k=\overline{1, \ldots, K}$. We will describe a procedure that constructs $u^{s+1}$ and $w_{k}^{s+1}$ given $u^{s}$ and $w_{k}^{s}(s=0,1, \ldots, k=1, \ldots, K)$ : 
1) the optimal structure of water use $x_{i}^{s}$ is determined independently by each user from the condition of profit maximization:

$$
\begin{gathered}
v_{i}\left(x_{i}\right)-u^{s} x_{i}-\sum_{k=1}^{K} w_{k}^{s} q_{i}^{k}\left(x_{i}\right) \rightarrow \max , \\
0 \leqslant x_{i} \leqslant \bar{x}_{i}, i=\overline{1, N} ;
\end{gathered}
$$

2) the new water price $u^{s+1}$ is determined from the condition

$$
u^{s+1}=\max \left(0, u^{s}+\rho_{s}\left(\sum_{i=1}^{N} x_{i}^{s}-F\right)\right)
$$

3) the new pollution charges $w_{k}^{s+1}$ are calculated from the formula

$$
\left.w_{s}^{s+1}=\max \left(0, w_{k}^{s}+\rho_{s} \sum_{i=1}^{N} q_{i}^{k}\left(x_{i}\right)-Q_{k}\right)\right), k=\overline{1, K}
$$

The convergence conditions of this algorithm are similar to the previous case. We additionally assume convexity of the functions $q_{i}^{k}\left(x_{i}\right)$ and existence of an interior point in the set defined by the constraints (14).

The procedure to determine the water prices and the pollution tax can be organized in the following way. Interstate monitoring in the basins of Syr Darya and Amu Darya will periodically provide readings of water use quantities and water pollution levels for each country. Water price and pollution charges will then be updated using the procedure (15), (16). The funds collected through these payments will be used to finance interstate ecological improvement programs in the region.

Direct application of this adaptive quasi-market procedure will obviously be a lengthy process until a nearly optimal price is set. It is therefore advisable to develop a negotiation procedure for determining the price of water and the pollution tax, modeled by the above-described algorithms. Before the negotiations begin, an "agency" is created with the authority to set prices and taxes. The Interstate Coordination Water Commission may act as such an "agency". The water users are the member countries. The negotiations are organized in the following way. The "agency" announces the current water prices $u^{s}$ and the pollution charges $w_{k}^{s}$. Then the users, independently of one another, determine the optimal water use levels $x_{i}^{s}$ and report them to the "agency". With the participation of "agency" representatives, the countries also compute the expected levels of water pollution $q_{i}^{k}\left(x_{i}^{s}\right)$. The "agency" aggregates the incoming information and calculates the differences

$$
\sum_{i=1}^{N} x_{i}^{s}-F \text { and } \sum_{i=1}^{N} q_{i}^{k}\left(x_{i}\right)-Q_{k}, k=\overline{1, K}
$$

Then the "agency" computes from (15), (16) the new water price $u^{s+1}$ and the new environmental tax $w_{k}^{s+1}$. Note that these negotiations are easily organized on a computer network linking the "agency" with the users. The "agency" initially has only information about the aggregated quantities $F$ and $Q_{k}$. Information about the functions $v_{i}(x)$ and $q_{i}^{k}(x)$ is available only to the users. The values of $x_{i}^{s}$ and $q_{i}^{k}\left(x_{i}^{s}\right)$ are received from the users directly at the network central computer, which computes the aggregated quantities $\sum_{i=1}^{N} x_{i}^{s}$ and $\sum_{i=1}^{N} q_{i}^{k}\left(x_{i}\right)$. This prevents undesirable disclosure of information, which is confidential for each user. Compared with the previous price formation procedure based on monitoring data, these negotiations are also advantageous to the users because they avoid the negative effect on their economies of the high nonoptimal prices set in the intermediate stages of the price-formation procedure.

A prototype software system for managing such a negotiation procedure is being developed at the Kiev University in cooperation with the Institute of Cybernetics of the Ukrainian Academy of Sciences. 


\section{REFERENCES}

1. Yu. Ermoliev, G. Klaassen, and A. Nentjes, Incomplete Information and the Cost-Efficiency of Ambient Charges, IIASA WP-93-72, Laxenburg (1993).

2. H. Nikaido, Convex Structures and Economic Analysis [Russian translation], Mir, Moscow (1972).

3. J. Hadley, Nonlinear and Dynamic Programming [Russian translation], Mir, Moscow (1967).

4. Yu. M. Ermol'ev, Stochastic Programming Methods [in Russian], Nauka, Moscow (1976). 
